\title{
The Role of Cerebrovascular Disease on Cognitive and Functional Status and Psychosis in Severe Alzheimer's Disease
}

\author{
Julia Kim ${ }^{\mathrm{a}, \mathrm{b}}$, Tom A. Schweizer ${ }^{\mathrm{a}, \mathrm{b}, \mathrm{c}, \mathrm{d}, \mathrm{e}}$, Corinne E. Fischer ${ }^{\mathrm{a}, \mathrm{f}}$ and David G. Munoz ${ }^{\mathrm{a}, \mathrm{g}, \mathrm{h}, *}$ \\ ${ }^{a}$ Keenan Research Centre for Biomedical Research, the Li Ka Shing Knowledge Institute, St. Michael's Hospital, \\ Toronto, ON, Canada \\ ${ }^{\mathrm{b}}$ Institute of Medical Sciences, University of Toronto, Toronto, ON, Canada \\ ${ }^{\mathrm{c}}$ Institute of Biomaterials and Biomedical Engineering, University of Toronto, Toronto, ON, Canada \\ ${ }^{\mathrm{d}}$ Department of Surgery, Division of Neurosurgery, Faculty of Medicine, University of Toronto, Toronto, \\ ON, Canada \\ ${ }^{\mathrm{e}}$ Division of Neurosurgery, St. Michael's Hospital, Toronto, ON, Canada \\ ${ }^{\mathrm{f}}$ Department of Psychiatry, Faculty of Medicine, University of Toronto, Toronto, ON, Canada \\ ${ }^{\mathrm{g}}$ Department of Laboratory Medicine and Pathobiology, University of Toronto, Toronto, ON, Canada \\ ${ }^{\mathrm{h}}$ Division of Pathology, St. Michael's Hospital, Toronto, ON, Canada
}

Accepted 10 August 2016

\begin{abstract}
.
Background: The pathophysiology behind psychosis in patients with Alzheimer's disease (AD) remains unknown. Recently, vascular risk factors have been recognized as important modifiers of the clinical presentation of AD.

Objective: The purpose of our study is to investigate the mechanism through which vascular risk factors mediate psychosis and whether or not it involves cerebrovascular lesions.

Methods: Data was provided by the National Alzheimer's Coordinating Centre. The Uniform Data Set was used to collect information on subject-reported history of vascular risk factors, clinician-reported state of cognitive performance, and presence of psychosis based on the Neuropsychiatric Inventory Questionnaire (NPI-Q). The Neuropathology Data Set was used to evaluate the presence of vascular lesions and the severity of AD pathology. Subjects with high probability of AD based on the NIA/AA Reagan criteria were included in the analysis.

Results: We identified 1,459 patients with high probability of AD and corresponding NPI-Q scores. We confirmed the association between hypertension and diabetes on psychosis, specifically in delusions and the co-occurrence of delusions and hallucinations. Furthermore, the presence of white matter rarefaction based on pathological evaluation was associated with hallucinations. A history of vascular risk factors was positively associated with vascular lesions. However, vascular lesions in the presence of vascular risk factors did not increase the likelihood of psychosis. Furthermore, vascular lesions were not associated with greater cognitive or functional impairments in this group with severe AD pathology.

Conclusion: Vascular risk factors and vascular lesions are independently associated with psychosis in patients with severe AD. However, vascular lesions are not the mechanism through which vascular risk factors mediate psychosis.
\end{abstract}

Keywords: Cerebrovascular diseases, delusions, dementia, hallucinations, infarction, neuropathology, pathology, risk factors, vascular

\footnotetext{
${ }^{*}$ Correspondence to: Dr. David G. Munoz, Department of Laboratory Medicine, Room 2-097 CC Wing, St. Michael's Hospital,
}

30 Bond Street. Toronto, ON, M5B 1W8, Canada. Tel.: +1416 864 5858; Fax: +1 416864 5648; E-mail: MunozD@smh.ca. 


\section{INTRODUCTION}

Psychosis is one of the common and disruptive conditions that occurs with Alzheimer's disease (AD). It is estimated that approximately $40 \%$ of patients with $\mathrm{AD}$ experience psychotic symptoms during the course of their illness [1]. Psychosis refers to a range of symptoms, generally categorized into delusions and hallucinations. Common delusional symptoms in $\mathrm{AD}$ include delusions of persecution, abandonment, infidelity, and misidentification. Hallucination symptoms are typically visual and auditory, but visual hallucinations are more common in $\mathrm{AD}$ [2]. Psychosis is often accompanied by behavioral disturbances [3-6] and a greater rate of cognitive decline [7-9], causing significant distress to both the patients and their caregivers $[10,11]$. However, the pathophysiology behind psychosis in $\mathrm{AD}$ remains largely unknown, limiting the ability to properly manage and treat patients.

Increasingly, cerebrovascular disease has been recognized as an important risk factor for the clinical manifestations of AD [12-16]. Several studies have shown that vascular factors significantly increase the likelihood of dementia [17]. Only recently, the role of cerebrovascular disease on psychosis in AD has been investigated. A study by Fischer and colleagues showed that vascular risk factors, but not plaque or tangle burden, are associated with psychosis in AD [18]. Other studies suggest that the presence of vascular pathology in certain regions of the brain, such as lacunar infarcts in the basal ganglia, impose a higher risk of developing delusional symptoms [19]. In the present study, we investigate the association between vascular risk factors and vascular pathology on cognitive and functional status and psychosis in patients with high probability of $\mathrm{AD}$, corresponding to severe pathology. Furthermore, we examine whether or not vascular pathology is the mechanism through which vascular risk factors mediate the development of psychosis.

\section{MATERIALS AND METHODS}

\section{Data source and subject criteria}

Data was obtained from the National Alzheimer's Coordinating Centre (NACC) encompassing records from approximately 30 Alzheimer's Disease Centers across the United States. The Uniform Data Set (UDS) and Neuropathology Data Set (NP) collected between September 2005 and December 2015 were analyzed.

The UDS was used to obtain demographical and clinical data. The demographic variables include age, sex, and education. The clinical variables comprise of informant-reported history of vascular risk factors, including hypertension, hypercholesterolemia, diabetes, and smoking (smoked more than 100 cigarettes in lifetime, total years smoked, and average number of packs per day). Clinician-reports for vascular risk factors were collected recently, and thus do not have corresponding neuropathology data. The duration of illness was calculated based on clinician's assessment on age at cognitive decline and age of death. The UDS was also used to collect clinicianreported scores on Mini-Mental State Examination (MMSE), Functional Activity Questionnaire (FAQ), and Global Clinical Dementia Rating (CDR). The presence and severity of psychotic symptoms (mild, moderate, severe), i.e., delusions or hallucinations in the month prior to the interview based on Neuropsychiatric Inventory Questionnaire, Quick version (NPI-Q) were also collected. The criteria for delusions on the NPI-Q are mainly persecutory delusions. The hallucinations symptoms include both visual and auditory hallucinations.

The NP was used to evaluate the severity of AD pathology, based on the density of neocortical neuritic plaque (CERAD score) and the Braak Stage for neurofibrillary degeneration. The NP was also used to collect data on the presence of vascular pathology, including microinfarcts (old microinfarcts not observed grossly), lacunae (small artery infarcts and/or hemorrhages less than $1 \mathrm{~cm}$ ), cerebral amyloid angiopathy (CAA), arteriosclerosis, and white matter rarefaction (subcortical arteriosclerotic leukoencephalopathy). The severity of white matter rarefaction (none, mild, moderate, or severe), which was recorded beginning in January 2014, was further categorized into minor (if none or mild) or major (if moderate or severe) severity of white matter rarefaction. Lewy body pathology was categorized as absent (if no Lewy bodies were found) or present (if Lewy bodies were observed in the brainstem, limbic region or amygdala, neocortical, olfactory bulb, or regions unspecified) as determined by alphasynuclein immunohistochemistry.

Patients with other primary etiological diagnosis, including brain injury, CNS neoplasm, Down's syndrome, and Huntington's disease on the UDS were excluded from the analysis. Subjects with high probability of AD based on the NIA/AA Reagan criteria, 
with CERAD score of 'frequent neuritic plaque' and Braak stage of $\mathrm{V}$ or VI were included (thus corresponding to severe AD pathology) [20].

Any positive score for delusions or hallucinations at any visit during the course of a patient's illness was considered positive for psychosis. Patients were categorized into never psychotic (AD-P), psychotic $(\mathrm{AD}+\mathrm{P})$, delusions only $(\mathrm{AD}+\mathrm{D})$, hallucinations only $(\mathrm{AD}+\mathrm{H})$, or co-occurrence of delusions and hallucinations $(\mathrm{AD}+\mathrm{DH})$.

\section{Statistical analysis}

All the statistical analyses were done using the statistical software SPSS Statistics 23.0. Each of the categories of psychosis, $\mathrm{AD}+\mathrm{P}, \mathrm{AD}+\mathrm{D}, \mathrm{AD}+\mathrm{H}$, and $\mathrm{AD}+\mathrm{DH}$ were independently analyzed against the AD-P group. The $\chi^{2}$ test was used to analyze categorical data. The independent samples $t$-test was used for continuous data with normal distribution. The Mann-Whitney test was used for continuous data if Kolmogorov-Smirnov test of normality was statistically significant. The ordinal regression analysis was used for ordinal data. ANCOVA was used when accounting for variance in the demographic or clinical characteristics between the diagnostic groups. No correction was applied for multiple testing. Statistical significance was assessed using $\alpha=0.05$.

\section{RESULTS}

The previous study by Fischer and colleagues using the NACC database collected between September 2005 and May 2012 identified 664 patients with high probability of AD using the NIA/AA Reagan criteria [18]. In our study, we identified 1459 patients with high probability of $\mathrm{AD}$, which includes overlapping patients from the previous study. Within this group, we identified $734 \mathrm{AD}-\mathrm{P}, 326 \mathrm{AD}+\mathrm{D}, 170 \mathrm{AD}+\mathrm{H}$, and 229 AD+DH.

\section{Demographic and clinical characteristics}

Subjects in the $\mathrm{AD}+\mathrm{P}$ and $\mathrm{AD}+\mathrm{H}$ were significantly younger at age of clinical visit compared to the AD-P counterparts. Subjects in the AD+H group were also younger at age at death. The age of onset of cognitive decline based on clinician's assessment was not statistically different between the diagnostic groups. The duration of illness was shorter in the $\mathrm{AD}+\mathrm{H}$ group compared to the AD-P group. The interval between last clinical visit and death was significantly shorter in all categories of psychosis compared to the AD-P counterparts. The average interval between last clinical visit and death were under two years in all of the diagnostic categories. There were no statistical differences between psychotic status and sex (Table 1).

\section{Vascular pathologies, Lewy bodies, and cognitive and functional status}

Within our criteria of high probability of $\mathrm{AD}$, there were no significant associations between vascular pathologies and cognitive or functional status, based on the MMSE, FAQ, and global CDR scores. The presence of Lewy body pathology was associated with lower MMSE scores, and higher FAQ scores, corresponding to greater cognitive and functional impairments (Table 2).

\section{Vascular risk factors and vascular pathology}

A history of vascular risk factors was positively associated with certain vascular pathologies. Patients

Table 1

The demographic and clinical distribution of subjects within each diagnostic categories (AD-P Never psychotic; AD+P Psychotic; AD+D Delusions only; $\mathrm{AD}+\mathrm{H}$ Hallucinations only; $\mathrm{AD}+\mathrm{DH}$ Co-occurrence of delusions and hallucinations). Each of the psychotic categories were independently analyzed against the non-psychotic group (AD-P)

\begin{tabular}{|c|c|c|c|c|c|c|c|c|c|c|}
\hline & \multicolumn{2}{|c|}{ AD-P } & \multicolumn{2}{|l|}{$\mathrm{AD}+\mathrm{P}$} & \multicolumn{2}{|c|}{$\mathrm{AD}+\mathrm{D}$} & \multicolumn{2}{|l|}{$\mathrm{AD}+\mathrm{H}$} & \multicolumn{2}{|c|}{$\mathrm{AD}+\mathrm{DH}$} \\
\hline & N/Mean & $\% / \mathrm{SD}$ & N/Mean & $\% / \mathrm{SD}$ & N/Mean & $\% / \mathrm{SD}$ & N/Mean & $\% / \mathrm{SD}$ & N/ean & $\% / \mathrm{SD}$ \\
\hline Age at clinical visit & $734 / 77.09$ & 10.58 & $725 / 76.02^{*}$ & 10.78 & $326 / 77.08$ & 10.24 & $170 / 74.43^{* *}$ & 10.84 & $229 / 75.68$ & 11.35 \\
\hline Age at death & $734 / 78.91$ & 10.4 & $725 / 78.11$ & 10.82 & $326 / 79.34$ & 10.22 & $170 / 76.35^{* *}$ & 10.99 & $229 / 77.66$ & 11.35 \\
\hline $\begin{array}{l}\text { Interval between last clinical } \\
\text { visit and death in years }\end{array}$ & $734 / 1.80$ & 1.77 & $725 / 1.31^{* *}$ & 1.35 & $326 / 1.45^{* *}$ & 1.49 & $170 / 1.28^{* *}$ & 1.32 & $229 / 1.14^{* *}$ & 1.14 \\
\hline Age onset & $714 / 69.13$ & 10.59 & $720 / 68.20$ & 10.75 & $324 / 69.43$ & 10.33 & $168 / 66.52$ & 10.52 & $228 / 67.68$ & 11.34 \\
\hline Duration of Illness & $714 / 9.56$ & 3.93 & $720 / 9.95$ & 3.97 & $324 / 9.90$ & 3.84 & $168 / 9.93^{* *}$ & 4.23 & $228 / 10.03$ & 3.95 \\
\hline \multicolumn{11}{|l|}{ Sex } \\
\hline Males & 411 & $56 \%$ & 383 & $53 \%$ & 176 & $54 \%$ & 92 & $54 \%$ & 115 & $50 \%$ \\
\hline Females & 323 & $44 \%$ & 342 & $47 \%$ & 150 & $46 \%$ & 78 & $46 \%$ & 114 & $50 \%$ \\
\hline
\end{tabular}

${ }^{*} p=0.010$ to $0.050 ;{ }^{* *} p \leq 0.010$. 
Table 2

The distribution of vascular lesions, Lewy bodies, and cognitive and functional impairments

\begin{tabular}{|c|c|c|c|c|c|c|}
\hline & \multicolumn{2}{|c|}{ MMSE } & \multicolumn{2}{|c|}{ FAQ } & \multicolumn{2}{|c|}{ Global CDR } \\
\hline & N/ Mean & $\overline{\mathrm{SD}}$ & N/ Mean & $\overline{\mathrm{SD}}$ & N/ Mean & $\mathrm{SD}$ \\
\hline \multicolumn{7}{|l|}{ Microinfarcts } \\
\hline Absent & $888 / 12.73$ & 8.47 & $1236 / 25.25$ & 7.15 & $1253 / 2.15$ & 0.88 \\
\hline Present & $180 / 12.97$ & 8.20 & $256 / 25.51$ & 6.47 & $260 / 2.15$ & 0.87 \\
\hline \multicolumn{7}{|l|}{ Lacunae } \\
\hline Absent & $728 / 12.40$ & 8.45 & $999 / 25.57$ & 6.87 & $1017 / 2.17$ & 0.87 \\
\hline Present & $128 / 12.40$ & 9.07 & $181 / 25.49$ & 7.22 & $183 / 2.22$ & 0.88 \\
\hline \multicolumn{7}{|c|}{ White matter rarefaction } \\
\hline Absent & $837 / 12.61$ & 8.46 & $1247 / 25.27$ & 7.08 & $1164 / 2.15$ & 0.88 \\
\hline Present & $193 / 12.74$ & 8.28 & $301 / 26.04$ & 6.30 & $305 / 2.24$ & 0.84 \\
\hline Lewy bodies & $* *$ & & $* *$ & & & \\
\hline Absent & $622 / 13.45$ & 8.50 & $900 / 24.98$ & 7.44 & $915 / 2.13$ & 0.90 \\
\hline Present & $442 / 11.82$ & 8.24 & $587 / 25.75$ & 6.36 & $592 / 2.16$ & 0.85 \\
\hline
\end{tabular}

${ }^{*} p=0.010$ to $0.050 ; *{ }^{*} p \leq 0.010$.

with a history of hypertension were significantly more likely to have microinfarcts, lacunae, and white matter rarefaction on pathological examination. Patients with a history of hypercholesterolemia or diabetes were more likely to have lacunae. A history of smoking was significantly associated with presence of white matter rarefaction. Lewy body pathology was negatively associated with hypertension, and was not associated with other vascular risk factors analyzed in this study (Table 3).

\section{Association of vascular risk factors, vascular pathologies, and Lewy bodies with psychosis}

In accordance with the previous study by Fischer and colleagues, we found a significant association between presence of psychosis and hypertension or diabetes [18]. This association was specific to patients with delusions and co-occurrence of delusions and hallucinations (Table 4). We did not find any associations between the presence of microinfarcts, lacunae, CAA, and arteriosclerosis and psychosis. However, a significant association was found between white matter rarefaction and psychosis, specifically AD+H. The presence of Lewy body pathology was positively associated with the $\mathrm{AD}+\mathrm{P}, \mathrm{AD}+\mathrm{H}$, and $\mathrm{AD}+\mathrm{DH}$ group compared to AD-P (Table 4).

\section{Vascular pathology as mediator}

Given that vascular risk factors and vascular pathologies are linked, and independently associated with psychosis, we then investigated whether vascular pathologies are the mediators through which vascular risk factors affect psychosis. However, in patients with a history of vascular risk factors, vascular pathologies, including white matter rarefaction, were not more common in any of the subgroups of psychosis compared to the AD-P group (Table 5). Lewy body pathology was not analyzed as a mediator because their only association with a vascular risk factor (hypertension) is negative. However, since Lewy bodies are positively associated with psychosis, their presence was used as a covariate in the analysis.

\section{DISCUSSION}

Several longitudinal studies in the elderly population have suggested that cerebrovascular disease is associated with increased likelihood of dementia [21-27]. However, an evidence-based review by Chui and colleagues show that there are no associations between vascular risk factors and AD pathology [28]. Studies with neuropathological confirmation have reported that the association between vascular pathology and dementia was observed only in patients with low to moderate, but not severe AD pathology $[29,30]$. Consistent with these findings, the present study shows that vascular pathologies do not affect cognitive or functional performance in subjects with high severity of AD pathology.

Importantly, our study confirms the finding that vascular risk factors are associated with increased risk of psychosis, specifically delusions [18]. However, the mechanism through which vascular risk factors affect the onset of psychosis remains unknown. In our study, we examined the role of vascular pathology as an intermediate mechanism through which vascular risk factors affect the onset of psychosis. We confirmed that risk factors are positively associated with vascular pathology, including microinfarcts, lacunae, and white matter rarefaction. Only one type of 


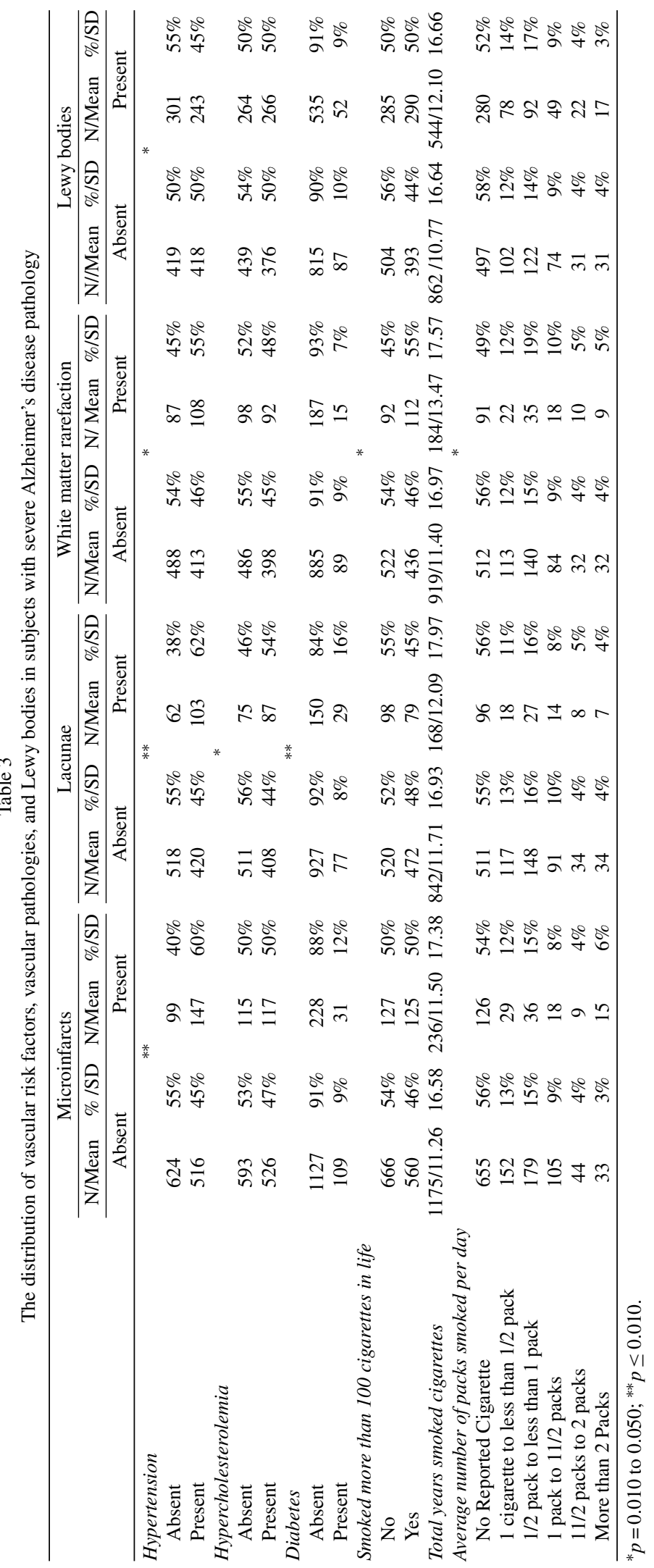


Table 4

The distribution of vascular risk factors, vascular pathologies, and degenerative pathology in each of the diagnostic categories of psychosis (AD-P Never psychotic; AD+P Psychotic; AD+D Delusions only AD+H Hallucinations only; AD+DH Co-occurrence of delusions and hallucinations). Each of the psychotic categories were independently analyzed against the non-psychotic group (AD-P)

\begin{tabular}{|c|c|c|c|c|c|c|c|c|c|c|}
\hline & \multicolumn{2}{|c|}{ AD-P } & \multicolumn{2}{|c|}{$\mathrm{AD}+\mathrm{P}$} & \multicolumn{2}{|c|}{$\mathrm{AD}+\mathrm{D}$} & \multicolumn{2}{|c|}{$\mathrm{AD}+\mathrm{H}$} & \multicolumn{2}{|c|}{$\mathrm{AD}+\mathrm{DH}$} \\
\hline & N/Mean & $\% / \mathrm{SD}$ & N/Mean & $\% / \mathrm{SD}$ & N/Mean & $\% / \mathrm{SD}$ & N/Mean & $\% / \mathrm{SD}$ & N/Mean & $\% / \mathrm{SD}$ \\
\hline \multicolumn{11}{|l|}{ Vascular Risk Factors } \\
\hline Hypertension & & & $* *$ & & $* *$ & & & & * & \\
\hline Absent & 369 & $56 \%$ & 327 & $49 \%$ & 145 & $47 \%$ & 82 & $55 \%$ & 100 & $47 \%$ \\
\hline Present & 292 & $44 \%$ & 347 & $51 \%$ & 165 & $53 \%$ & 67 & $45 \%$ & 115 & $53 \%$ \\
\hline \multicolumn{11}{|l|}{ Hypercholesterolemia } \\
\hline Absent & 346 & $53 \%$ & 328 & $50 \%$ & 143 & $49 \%$ & 83 & $56 \%$ & 102 & $49 \%$ \\
\hline Present & 306 & $47 \%$ & 322 & $50 \%$ & 151 & $51 \%$ & 66 & $44 \%$ & 105 & $51 \%$ \\
\hline Diabetes & & & & & $*$ & & & & $*$ & \\
\hline Absent & 672 & $92 \%$ & 639 & $89 \%$ & 288 & $89 \%$ & 155 & $95 \%$ & 196 & $87 \%$ \\
\hline Present & 57 & $8 \%$ & 75 & $11 \%$ & 36 & $11 \%$ & 9 & $5 \%$ & 30 & $13 \%$ \\
\hline \multicolumn{11}{|c|}{ Smoked more than 100 cigarettes in life } \\
\hline No & 371 & $51 \%$ & 392 & $55 \%$ & 371 & $51 \%$ & 92 & $55 \%$ & 126 & $56 \%$ \\
\hline Yes & 351 & $49 \%$ & 319 & $45 \%$ & 351 & $49 \%$ & 75 & $45 \%$ & 100 & $44 \%$ \\
\hline Total years smoked cigarettes & $692 / 11.78$ & 16.93 & $675 / 11.00$ & 16.62 & $303 / 11.22$ & 16.63 & $158 / 9.49$ & 14.66 & $214 / 11.79$ & 17.91 \\
\hline \multicolumn{11}{|c|}{ Average number of packs smoked per day } \\
\hline No Reported Cigarette & 362 & $49 \%$ & 389 & $54 \%$ & 172 & $53 \%$ & 91 & $54 \%$ & 126 & $55 \%$ \\
\hline 1 cigarette to less than $1 / 2$ pack & 93 & $13 \%$ & 86 & $11 \%$ & 35 & $11 \%$ & 22 & $13 \%$ & 29 & $13 \%$ \\
\hline $1 / 2$ pack to less than 1 pack & 119 & $16 \%$ & 90 & $12 \%$ & 42 & $13 \%$ & 1 & $11 \%$ & 29 & $13 \%$ \\
\hline 1 pack to $11 / 2$ packs & 62 & $8 \%$ & 55 & $8 \%$ & 22 & $7 \%$ & 12 & $7 \%$ & 21 & $9 \%$ \\
\hline $11 / 2$ packs to 2 packs & 25 & $3 \%$ & 28 & $4 \%$ & 15 & $5 \%$ & 4 & $2 \%$ & 9 & $4 \%$ \\
\hline More than 2 Packs & 25 & $3 \%$ & 23 & $3 \%$ & 11 & $3 \%$ & 9 & $5 \%$ & 3 & $1 \%$ \\
\hline \multicolumn{11}{|l|}{ Vascular Pathology } \\
\hline \multicolumn{11}{|l|}{ Microinfarcts } \\
\hline Absent & 599 & $82 \%$ & 608 & $84 \%$ & 267 & $82 \%$ & 149 & $88 \%$ & 192 & $84 \%$ \\
\hline Present & 134 & $18 \%$ & 117 & $16 \%$ & 59 & $18 \%$ & 21 & $12 \%$ & 37 & $16 \%$ \\
\hline \multicolumn{11}{|l|}{ Lacunae } \\
\hline Absent & 483 & $86 \%$ & 487 & $85 \%$ & 210 & $84 \%$ & 131 & $91 \%$ & 146 & $81 \%$ \\
\hline Present & 80 & $14 \%$ & 87 & $15 \%$ & 40 & $16 \%$ & 13 & $9 \%$ & 34 & $19 \%$ \\
\hline \multicolumn{11}{|l|}{ Cerebral Amyloid Angiopathy (CAA) } \\
\hline None & 141 & $19 \%$ & 128 & $18 \%$ & 55 & $17 \%$ & 31 & $18 \%$ & 42 & $18 \%$ \\
\hline Mild & 252 & $34 \%$ & 242 & $33 \%$ & 104 & $32 \%$ & 55 & $32 \%$ & 83 & $36 \%$ \\
\hline Moderate & 199 & $27 \%$ & 197 & $27 \%$ & 94 & $29 \%$ & 48 & $28 . \%$ & 55 & $24 \%$ \\
\hline Severe & 129 & $18 \%$ & 136 & $19 \%$ & 69 & $21 \%$ & 28 & $16 \%$ & 39 & $17 \%$ \\
\hline White matter rarefaction & & & & & & & $*$ & & & \\
\hline Absent & 481 & $84 \%$ & 454 & $80 \%$ & 204 & $82 \%$ & 111 & $78 \%$ & 139 & $78 \%$ \\
\hline Present & 89 & $16 \%$ & 116 & $20 \%$ & 44 & $18 \%$ & 32 & $22 \%$ & 40 & $22 \%$ \\
\hline \multicolumn{11}{|l|}{ Arteriolosclerosis } \\
\hline None & 134 & $18 \%$ & 123 & $17 \%$ & 54 & $17 \%$ & 28 & $17 \%$ & 41 & $18 \%$ \\
\hline Mild & 213 & $29 \%$ & 219 & $30 \%$ & 99 & $30 \%$ & 48 & $28 \%$ & 72 & $31 \%$ \\
\hline Moderate & 190 & $26 \%$ & 187 & $26 \%$ & 89 & $27 \%$ & 47 & $28 \%$ & 51 & $22 \%$ \\
\hline Severe & 90 & $12 \%$ & 102 & $14 \%$ & 45 & $14 \%$ & 20 & $12 \%$ & 37 & $16 \%$ \\
\hline \multicolumn{11}{|l|}{ Degenerative Pathology } \\
\hline Lewy bodies & & & $* *$ & & & & $* *$ & & $* *$ & \\
\hline Absent & 467 & $64 \%$ & 402 & $56 \%$ & 196 & $60 \%$ & 87 & $51 \%$ & 119 & $52 \%$ \\
\hline Present & 262 & $36 \%$ & 322 & $44 \%$ & 130 & $40 \%$ & 83 & $49 \%$ & 109 & $48 \%$ \\
\hline
\end{tabular}

${ }^{*} p=0.010$ to $0.050 ;{ }^{* *} p \leq 0.010$.

vascular pathology, specifically presence of white matter rarefaction, was related to a form of psychosis, hallucinations. Furthermore, vascular pathology in the presence of vascular risk factors did not increase the likelihood of psychosis, indicating that the contributions of hypertension or diabetes to the development of psychosis are mediated by mechanisms other than vascular lesions. Alternatively, the location, rather than the presence of vascular lesions, would be the critical factor, but this is not the case when the effects of vascular lesions on cognitive performance in subjects with moderate AD load are considered [29, 30]. Previous studies on white matter hyperintensities on psychosis have produced mixed results. Many studies show no correlation between periventricular and white matter hyperintensities 
Table 5

The distribution of vascular lesions and psychosis each diagnostic categories of psychosis in presence of vascular risk factors in subjects with high probability of AD. (AD-P Never psychotic; AD+P Psychotic; AD+D Delusions only; AD+H Hallucinations only; AD+DH Cooccurrence of delusions and hallucinations). Each of the psychotic categories were independently analyzed against the non-psychotic group (AD-P)

\begin{tabular}{|c|c|c|c|c|c|c|c|c|c|c|}
\hline & \multicolumn{2}{|c|}{ AD-P } & \multicolumn{2}{|c|}{$\mathrm{AD}+\mathrm{P}$} & \multicolumn{2}{|c|}{$\mathrm{AD}+\mathrm{D}$} & \multicolumn{2}{|c|}{$\mathrm{AD}+\mathrm{H}$} & \multicolumn{2}{|c|}{$\mathrm{AD}+\mathrm{DH}$} \\
\hline & N/Mean & $\% / \mathrm{SD}$ & N/Mean & $\% / \mathrm{SD}$ & N/Mean & $\%$ & N/Mean & $\% / \mathrm{SD}$ & N/Mean & $\% / \mathrm{SD}$ \\
\hline \multicolumn{11}{|c|}{$\begin{array}{l}\text { History of Hypertension }+ \text {, } \\
\text { Microinfarcts }\end{array}$} \\
\hline Absent & 223 & $77 \%$ & 274 & $79 \%$ & 127 & $77 \%$ & 58 & $87 \%$ & 89 & $77 \%$ \\
\hline Present & 68 & $23 \%$ & 73 & $21 \%$ & 38 & $23 \%$ & 9 & $13 \%$ & 26 & $23 \%$ \\
\hline \multicolumn{11}{|l|}{ Lacunae } \\
\hline Absent & 183 & $81 \%$ & 217 & $79 \%$ & 97 & $78 \%$ & 52 & $90 \%$ & 68 & $75 \%$ \\
\hline Present & 43 & $19 \%$ & 56 & $21 \%$ & 27 & $22 \%$ & 6 & $10 \%$ & 23 & $25 \%$ \\
\hline \multicolumn{11}{|c|}{ White matter rarefaction } \\
\hline Absent & 216 & $77 \%$ & 258 & $76 \%$ & 129 & $80 \%$ & 49 & $74 \%$ & 80 & $71 \%$ \\
\hline Present & 65 & $23 \%$ & 82 & $24 \%$ & 32 & $20 \%$ & 17 & $26 \%$ & 33 & $29 \%$ \\
\hline \multicolumn{11}{|c|}{ History of Hypercholesterolemia + } \\
\hline $\begin{array}{l}\text { Microinjar } \\
\text { Absent }\end{array}$ & \multicolumn{8}{|c|}{ Microinfarcts } & & $81 \%$ \\
\hline Present & 62 & $20 \%$ & 52 & $16 \%$ & 24 & $16 \%$ & 8 & $12 \%$ & 20 & $19 \%$ \\
\hline \multicolumn{11}{|l|}{ Lacunae } \\
\hline Absent & 194 & $84 \%$ & 203 & $82 \%$ & 87 & $78 \%$ & 53 & $91 \%$ & 63 & $79 \%$ \\
\hline Present & 37 & $16 \%$ & 46 & $18 \%$ & 24 & $22 \%$ & 5 & $9 \%$ & 17 & $21 \%$ \\
\hline \multicolumn{11}{|c|}{ White matter rarefaction } \\
\hline Absent & 231 & $80 \%$ & 246 & $78 \%$ & 117 & $79 \%$ & 53 & $82 \%$ & 76 & $75 \%$ \\
\hline Present & 58 & $20 \%$ & 68 & $22 \%$ & 31 & $21 \%$ & 12 & $18 \%$ & 25 & $25 \%$ \\
\hline \multicolumn{11}{|c|}{ History of Smoking + } \\
\hline \multicolumn{11}{|c|}{ Microinfarcts } \\
\hline Absent & 282 & $80 \%$ & 266 & $85 \%$ & 117 & $81 \%$ & 65 & $87 \%$ & 84 & $88 \%$ \\
\hline Present & 69 & $20 \%$ & 48 & $15 \%$ & 27 & $19 \%$ & 10 & $13 \%$ & 11 & $12 \%$ \\
\hline \multicolumn{11}{|l|}{ Lacunae } \\
\hline Absent & 241 & $85 \%$ & 218 & $86 \%$ & 99 & $86 \%$ & 59 & $94 \%$ & 60 & $79 \%$ \\
\hline Present & 41 & $15 \%$ & 36 & $14 \%$ & 16 & $14 \%$ & 4 & $6 \%$ & 16 & $21 \%$ \\
\hline \multicolumn{11}{|c|}{ White matter rarefaction } \\
\hline Absent & 282 & $79 \%$ & 302 & $79 \%$ & 128 & $77 \%$ & 73 & $80 \%$ & 101 & $82 \%$ \\
\hline Present & 74 & $21 \%$ & 79 & $21 \%$ & 39 & $23 \%$ & 18 & $20 \%$ & 22 & $18 \%$ \\
\hline
\end{tabular}

${ }^{*} p=0.010$ to $0.050 ;{ }^{* *} p \leq 0.010$.

and psychosis [31-33]. Other studies indicate that regional white matter hyperintensities affect development of delusional symptoms [34, 35]. However, these findings on white matter hyperintensities are derived from imaging studies. The results from our study based on neuropathological data suggest that white matter rarefaction increases the likelihood of psychosis, specifically hallucinations.

There are some limitations to the present study. One of the limitations of the study is that multiple univariate tests were employed in the statistical analysis, which may inflate the rate of type I error. We, as others before us, have not corrected for multiple testing in this exploratory stage [36, 37]. Another limitation is the time gap between last clinical visit and the time of death. The average time interval between last clinical visit and death in years was within two years, but the progression of the illness possibly varied among the subject population.
Furthermore, vascular risk factors analyzed in this study are subject or caregiver reported historical data, and whether the condition is still active or has been treated is not available. The NACC database started to implement clinician-reported measures since 2015, which would provide a numerical evaluation for accessing vascular risk factors at time of the visit. With respect to our analysis on cognitive performance, the results may be reflective of a floor effect given that patients with severe AD have limited functional and cognitive capacity. The choice of high AD pathology load is inseparable from high probability that the dementia is due to $\mathrm{AD}$, the rationale for our choice of inclusion criterion. The presentation of psychosis collected on the NPI-Q also introduces some limitations. First of all, NPI-Q records presentation of psychosis during the last month prior to clinical visit, and does not take into account the trajectory of psychotic symptoms over time. Secondly, the criteria 
for delusions on NPI-Q are persecutory delusions. Therefore, the association between vascular risk factors and other types of delusions in $\mathrm{AD}$ remains to be further investigated.

In summary, we demonstrate the importance of cerebrovascular disease in the clinical manifestation of psychosis, but not in cognitive performance in subjects with severe AD pathology. However, the mechanism through which vascular risk factors affects psychosis is not mediated through just the presence of vascular pathology. It is possible that vascular risk factors and vascular lesions trigger widespread alterations in the brain, which in the presence of moderate AD load results in cognitive impairment, but in the presence of severe $\mathrm{AD}$ results in psychosis. Prospective studies investigating the trajectories of vascular pathology and clinical manifestation $\mathrm{AD}$ will help to better understand the pathophysiology of AD.

\section{ACKNOWLEDGMENTS}

The NACC database is funded by NIA/NIH Grant U01 AG016976. NACC data are contributed by the NIA-funded ADCs: P30 AG019610 (PI Eric Reiman, MD), P30 AG013846 (PI Neil Kowall, MD), P50 AG008702 (PI Scott Small, MD), P50 AG025688 (PI Allan Levey, MD, PhD), P50 AG047266 (PI Todd Golde, MD, PhD), P30 AG010133 (PI Andrew Saykin, PsyD), P50 AG005146 (PI Marilyn Albert, PhD), P50 AG005134 (PIBradley Hyman, MD, PhD), P50 AG016574 (PI Ronald Petersen, MD, PhD), P50 AG005138 (PI Mary Sano, PhD), P30 AG008051 (PI Steven Ferris, PhD), P30 AG013854 (PI M. Marsel Mesulam, MD), P30 AG008017 (PI Jeffrey Kaye, MD), P30 AG010161 (PI David Bennett, MD), P50 AG047366 (PI Victor Henderson, MD, MS), P30 AG010129(PICharles DeCarli, MD), P50 AG016573 (PI Frank LaFerla, PhD), P50 AG016570 (PI MarieFrancoise Chesselet, MD, PhD), P50 AG005131 (PI Douglas Galasko, MD), P50 AG023501 (PI Bruce Miller, MD), P30 AG035982 (PI Russell Swerdlow, MD), P30 AG028383 (PI Linda Van Eldik, PhD), P30 AG010124 (PI John Trojanowski, MD, PhD), P50 AG005133 (PI Oscar Lopez, MD), P50 AG005142 (PI Helena Chui, MD), P30 AG012300 (PI Roger Rosenberg, MD), P50 AG005136 (PI Thomas Montine, MD, PhD), P50 AG033514 (PI Sanjay Asthana, MD, FRCP), P50 AG005681 (PI John Morris, MD), and P50 AG047270 (PI Stephen Strittmatter, MD, $\mathrm{PhD}$ )
Authors' disclosures available online (http://j-alz. com/manuscript-disclosures/16-0506r1).

\section{REFERENCES}

[1] Ropacki SA, Jeste DV (2005) Epidemiology of and risk factors for psychosis of Alzheimer's disease: A review of 55 studies published from 1990 to 2003. Am J Psychiatry 162, 2022-2030.

[2] Murray PS, Kumar S, Demichele-Sweet M, Sweet RA (2014) Psychosis in Alzheimer's disease. Biol Psychiatry 75, 542-552.

[3] Lopez OL, Wisniewski SR, Becker JT, Boller F, DeKosky ST (1999) Psychiatric medication and abnormal behavior as predictors of progression in probable Alzheimer disease. Arch Neurol 56, 1266-1272.

[4] Gilley DW, Wilson RS, Beckett LA, Evans DA (1997) Psychotic symptoms and physically aggressive behavior in Alzheimer's disease. J Am Geriatr Soc 45, 1074-1079.

[5] Lyketsos CG, Steinberg M, Tschanz JT, Norton MC, Steffens DC, Breitner JC (2000) Mental and behavioral disturbances in dementia: Findings from the Cache County Study on Memory in Aging. Am J Psychiatry 157, 708-714.

[6] Cummings JL, Brodaty H, Ballard CG, Lyketsos CG, Grossberg GT, Robert P, Gauthier S (2009) Management of agitation and aggression associated with Alzheimer disease. Nat Rev Neurol 5, 245-255.

[7] Gilley DW, Whalen ME, Wilson RS, Bennett DA (1991) Hallucinations and associated factors in Alzheimer's disease. J Neuropsychiatry Clin Neurosci 3, 371-376.

[8] Chui HC, Lyness SA, Sobel E, Schneider LS (1994) Extrapyramidal signs and psychiatric symptoms predict faster cognitive decline in Alzheimer's disease. Arch Neurol 51, 676-681.

[9] Fischer CE, Ismail Z, Schweizer TA (2012) Delusions increase functional impairment in Alzheimer's disease. Dement Geriatr Cogn Disord 33, 393-399.

[10] Everitt DE, Fields DR, Soumerai SS, Avorn J (1991) Resident behavior and staff distress in the nursing home. $J \mathrm{Am}$ Geriatr Soc 39, 792-798.

[11] Kaufer DI, Cummings JL, Christine D, Bray T, Castellon S, Masterman D, MacMillan A, Ketchel P, DeKosky ST (1998) Assessing the impact of neuropsychiatric symptoms in Alzheimer's disease: The neuropsychiatric inventory caregiver distress scale. J Am Geriatr Soc 46, 210-215.

[12] de Bruijn RF, Ikram MA (2014) Cardiovascular risk factors and future risk of Alzheimer's disease. BMC Med 12, 130.

[13] Villeneuve S, Jagust W (2015) Imaging vascular disease and amyloid in the aging brain: Implications for treatment. J Prev Alzheimers Dis 1, 64-70.

[14] Kalaria RN, Akinyemi R, Ihara M (2012) Does vascular pathology contribute to Alzheimer changes? J Neurol Sci 322, 141-147.

[15] Qiu C, Xu W, Winblad B, Fratiglioni L (2010) Vascular risk profiles for dementia and Alzheimer's disease in very old people: A population-based longitudinal study. JAlzheimers Dis 20, 293-300.

[16] Reitz C, Tang M, Schupf N, Manly JJ, Mayeux R, Luchsinger JA (2010) A summary risk score for the prediction of Alzheimer disease in elderly persons. Arch Neurol 67, 835-841.

[17] Gorelick PB, Scuteri A, Black SE, Decarli C, Greenberg SM, Iadecola C, Launer LJ, Laurent S, Lopez OL, Nyenhuis D, Petersen RC, Schneider JA, Tzourio C, Arnett 
DK, Bennett DA, Chui HC, Higashida RT, Lindquist R, Nilsson PM, Roman GC, Sellke FW, Seshadri S, American Heart Association Stroke Council, Council on Epidemiology and Prevention, Council on Cardiovascular Nursing, Council on Cardiovascular Radiology and Intervention, and Council on Cardiovascular Surgery, and Anesthesia, on behalf of the American Heart Association Stroke Council, Council on Epidemiology and Prevention, Council on Cardiovascular Nursing, Council on Cardiovascular Radiology and Intervention, and Council on Cardiovascular Surgery, and Anesthesia (2011) Vascular contributions to cognitive impairment and dementia: A statement for healthcare professionals from the American Heart Association/American Stroke Association. Stroke 42, 2672-2713.

[18] Fischer CE, Qian W, Schweizer TA, Millikin CP, Ismail Z, Smith EE, Lix LM, Shelton P, Munoz DG (2015) Lewy bodies, vascular risk factors, and subcortical arteriosclerotic leukoencephalopathy, but not Alzheimer pathology, are associated with development of psychosis in Alzheimer's disease. J Alzheimers Dis 50, 283-295.

[19] Palmqvist S, Sarwari A, Wattmo C, Bronge L, Zhang Y, Wahlund LO, Nagga K (2011) Association between subcorticial lesions and behavioural and psychological symptoms in patients with Alzheimer's disease. Dement Geriatr Cogn Disord 32, 417-423.

[20] Hyman BT, Trojanowski JQ (1997) Consensus recommendations for the postmortem diagnosis of Alzheimer disease from the National Institute on Aging and the Reagan Institute Working Group on diagnostic criteria for the neuropathological assessment of Alzheimer disease. $\mathrm{J} \mathrm{Neu}$ ropathol Exp Neurol 56, 1095-1097.

[21] Arvanitakis Z, Leurgans SE, Barnes LL, Bennett DA, Schneider JA (2011) Microinfarct pathology, dementia, and cognitive systems. Stroke 42, 722-727.

[22] Hughes TM, Sink KM (2016) Hypertension and its role in cognitive function: Current evidence and challenges for the future. Am J Hypertens 29, 149-157.

[23] White L, Small BJ, Petrovitch H, Ross GW, Masaki K, Abbott RD, Hardman J, Davis D, Nelson J, Markesbery W (2005) Recent clinical-pathologic research on the causes of dementia in late life: Update from the Honolulu-Asia Aging Study. J Geriatr Psychiatry Neurol 18, 224-227.

[24] Iadecola C (2013) The pathobiology of vascular dementia. Neuron 80, 844-866.

[25] Petrovitch H, Ross GW, Steinhorn SC, Abbott RD, Markesbery W, Davis D, Nelson J, Hardman J, Masaki K, Vogt MR, Launer L, White LR (2005) AD lesions and infarcts in demented and non-demented Japanese-American men. Ann Neurol 57, 98-103.
[26] Scarmeas N, Brandt J, Albert M, Hadjigeorgiou G, Papadimitriou A, Dubois B, Sarazin M, Devanand D, Honig L, Marder K, Bell K, Wegesin D, Blacker D, Stern Y (2005) Delusions and hallucinations are associated with worse outcome in Alzheimer disease. Arch Neurol 62, 1601-1608.

[27] Qiu C, Winblad B, Fratiglioni L (2005) The age-dependent relation of blood pressure to cognitive function and dementia. Lancet Neurol 4, 487-499.

[28] Chui HC, Zheng L, Reed BR, Vinters HV, Mack WJ (2012) Vascular risk factors and Alzheimer's disease: Are these risk factors for plaques and tangles or for concomitant vascular pathology that increases the likelihood of dementia? An evidence-based review. Alzheimers Res Ther 4, 1-36.

[29] Snowdon DA (1997) Brain infarction and the clinical expression of Alzheimer disease. The Nun Study. JAMA 277, 813-817.

[30] Esiri MM, Nagy Z, Smith MZ, Smith AD, Barnetson L (1999) Cerebrovascular disease and threshold for dementia in the early stages of Alzheimer's disease. Lancet 354, 919920.

[31] Harrell LE, Duvall E, Folks DG, Duke L, Bartolucci A, Conboy T, Callaway R, Kerns D (1991) The relationship of high-intensity signals on magnetic resonance images to cognitive and psychiatric state in Alzheimer's disease. Arch Neurol 48, 1136-1140.

[32] Lopez OL, Becker JT, Rezek D, Wess J, Boiler F, Reynolds CF, Panisset M (1992) Neuropsychiatric correlates of cerebral white-matter radiolucencies in probable Alzheimer's disease. Arch Neurol 49, 828-834.

[33] Zanetti MV, Schaufelberger MS, de Castro CC, Menezes PR, Scazufca M, McGuire PK, Murray RM, Busatto GF (2008) White-matter hyperintensities in first-episode psychosis. Br J Psychiatry 193, 25-30.

[34] Binetti G, Padovani A, Magni E, Bianchetti A, Scuratti A, Lenzi GL, Trabucchi M (1995) Delusions and dementia: Clinical and CT correlates. Acta Neurol Scand 91, 271-275.

[35] Lee DY, Choo IH, Kim KW, Jhoo JH, Youn JC, Lee UY, Woo JI (2006) White matter changes associated with psychotic symptoms in Alzheimer's disease patients. J Neuropsychiatry Clin Neurosci 18, 191-198.

[36] Chung EJ, Babulal GM, Monsell SE, Cairns NJ, Roe CM, Morris JC (2015) Clinical features of Alzheimer disease with and without Lewy bodies. JAMA Neurol 72, 789-796.

[37] Hsiao JJ, Lu PH, Grill JD, Teng E (2015) Longitudinal declines in instrumental activities of daily living in stable and progressive mild cognitive impairment. Dement Geriatr Cogn Disord 39, 12-24. 